\title{
Koroner Arterlerin Bölütlenmesi Temelli Bir Karar Destek Sistemi
}

\author{
Turab SELÇUK ${ }^{1}$, Mehmet TEKINALP², Ahmet ALKAN ${ }^{1}$ \\ ${ }^{1}$ Kahramanmaraş Sütçü İmam Üniversitesi, Elektrik Elektronik Mühendisliği, Kahramanmaraş, Türkiye \\ ${ }^{2}$ Kahramanmaraş Necip Fazıl Şehir Hastanesi, Kardiyoloji Klini ği, Kahramanmaraş, Türkiye
}

\begin{abstract}
ÖZET: Kalbi besleyen koroner arterlerin anatomisinin bilinmesi kalp hastalıklarının tanısında büyük önem arz etmektedir. Koroner arterlerden sağ koroner arter (RCA), sol ana koroner arter (LMCA), sol ön inen arter (LAD) ve sirkumflex arter $(\mathrm{Cx})$ veya alt dallardaki arterlerden birinde meydana gelebilecek bir tıkanmanın büyüklüğü tedavi yöntemi için önem arz etmektedir. Yapılan çalışmada koroner arterlerin bölütlenmesi temelli bir tanı destek sistemi oluşturulmuştur. Bu amaçla, kalp anjiyografi görüntülerine sayısal görüntü işleme teknikleri uygulanarak koroner arterlerde meydana gelen daralmanın yüzdesinin belirlenmesine yönelik bir yazılım geliştirilmiştir. Çalışma uzman kardiyolog gözetiminde gerçekleştirilmiş olup yazılımda elde edilen sonuçlar uzman doktorun elde ettiği sonuçlarla karşılaştırılmıştır. Beş görüntü için $\% 5$ ile $\% 12$ arasında geri kalanlar için ise $\% 1$ ile $\% 5$ arasında bir darlık yüzdeleri arasında farkı olduğu gözlemlenmiştir. Çalışmanın bölütleme başarımı ise ZSI (zijdenbos similarity index) başarım belirleme indeksine göre tespit edilmiştir. Elde edilen ZSI değerleri, literatürde oldukça başarılı sayılabilecek (\%78\%91 arasında) değerlerdedir. Elde edilen bölütleme sonuçları, önerilen sistemin klinik ve araştırma çalışmalarında tanı destek aracı olarak kullanılabileceğini göstermiştir.
\end{abstract}

Anahtar Kelimeler: Koroner arter, Görüntü işleme, Anjiyoplasti

\section{The Segmentation of the Coronary Arteries Based Decision Support System}

\begin{abstract}
The knowledge of the anatomy of the coronary arteries that feed the heart is of great importance in the diagnosis of heart diseases. Size of a blockage that can occur in right coronary artery (RCA), left main coronary artery (LMCA), left anterior descending artery (LAD) and circumflex artery (Cx) or the one of the arteries in the lower branches is very important for the treatment. In this study, coronary arteries segmentation based diagnostic support system was proposed. For this purpose, a software has been developed for determining the percentage of the contraction occurring in coronary arteries by applying digital image processing techniques to cardiac angiography images. The study has been carried out in the expert supervision of cardiologist and the obtained coronary arteries segmentation results were compared with the manually segmented by the cardiologist. The vascular stenosis ratio differences were observed between $\% 5$ to $\% 12$ for five images and $1 \%$ to $5 \%$ for the rest of the data. The segmentation succes of the study was determined by using ZSI (zijdenbos similarity index). The resulting ZSI values (between \% 78$\% 91$ ) were between $\% 78$ and $\% 91$ that can be considered as a successful segmentation in the literature. Obtained segmentation results showed that the proposed system can be used as a diagnostic support tool in clinical and research studies.
\end{abstract}

Keywords: Coronary artery, Image Processing, Angioplasty

\section{GíRiş}

Atardamarlar kalpten pompalanan kanın tüm vücut dokularına taşındığ Duvarı elastiki bir yapıda olup kalp, beyin, akciğerler, karaciğer, mide, pankreas, kaslar, bacaklar gibi tüm dokular, kandan oksijen alarak beslenmeyi bu arterler sayesinde gerçekleşmektedir. Bu arterlerden birisi belki de en önemlisi, kalbi besleyen koroner arterlerdir. Bu koroner arterlerde meydana gelen bir daralma veya tıkanma ile kan akımının kısmi ya da tam kesilmesine bağlı olarak ortaya çıkan hastalıklara koroner arter hastalığı denilmektedir [1]. İstatiksel sonuçlara göre insan sağlığını tehdit eden önemli hastalıkların başında kardiyovasküler hastalıklar gelmektedir [2-3]. Bu tür hastalıkların, ölüme sebebiyet verme sıralamalarında bütün hastalıklar arasında ilk sırayı aldığı bilinmektedir [4]. $\mathrm{Bu}$ nedenle erken tanı ve teşhis hayati önem taşımaktadır. Uygulanacak tedavi yöntemi damarın tıkanıklık derecesine göre belirlendiğinden, tıkalı damarın bölütlenmesi koroner arter hastalıklarında önemli bir çalışma konusu olmuştur.

Hızla gelişen görüntüleme teknolojisi sayesinde, birçok hastalık gibi kalp hastalıklarının da erken tanısı yapılabilmektedir. $\mathrm{Bu}$ amaçla BT (Bilgisayarlı Tomografi) ya da anjiyografi görüntülerinden, koroner arterlerde meydana gelen daralma, tıkanıklık veya anevrizma gibi durumların önceden belirlenmesine yönelik birçok çalışma yapılmıştır [5-6].

Zhou ve arkadaşları yapmış oldukları bir çalışmada damarların yarı otomatik bölütlenmesine yönelik Gabor 
filtresi ve Hessian matris analizi yöntemlerini kullanmışlardır [7]. Khaleel ve arkadaşları yapmış oldukları çalışmada [8] damar ağacı çıkarımında gauss filtresinin farklı varyans değerinde oluşan sonuca göre bir eşikleme değeri belirlenerek damarların bölütlenmesi gerçekleştirilmiştir. Bir diğer çalışmada ise damar çıkarımı için yeni bir morfolojik yöntem sunulmuştur. Top-Hat operatörü kullanılarak görüntü kontrastı iyileştirilmiş ve damarların belirginleşmesi sağlanmıştır. Daha sonra eşikleme yöntemiyle damar ağacı yapısı ortaya çıkartılmıştır [9]. Ouian ve arkadaşları ise çalışmalarında [10] damar ağacının çıkarımı için morfolojik işleme tekniklerini kullanmışlardır. Öncelikle Top-Hat işlemi ile damarın ince ve kalın bölgeleri belirlenmiş daha sonra yarı eşikleme işlemi kullanılmıştır. Damar ağacını oluşturma kısmı ise etiketleme işlemi ile sağlanmıştır.

$\mathrm{Bu}$ çalışmada koroner arter hastalıklarında kullanılacak tedavi yönteminin belirlenmesi amaciyla yarı otomatik bir yazılım oluşturulmuştur. Oluşturulan bu yazılım sayesinde uzman doktorun gözlem sonucunda, işaretleyerek belirlediği tıkalı kısım bölütlenerek darlık yüzdesi elde edilmektedir. Çalışmanın ikinci kısmında kullanılan veri kümesi ve yöntemlerden bahsedilmiştir. Üçüncü kısımda elde edilen sonuçlar ve çalışmanın başarımı ele alınmış olup dördüncü kısımda ise elde edilen sonuçlara yer verilmiştir. Çalışmaya ait akış diyagramı şekil 1.1 'de verilmiştir.

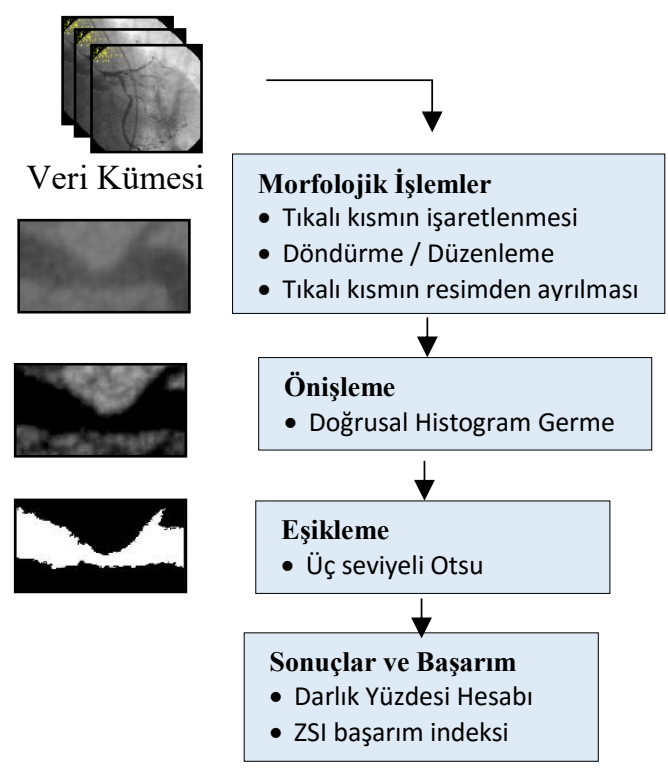

Şekil 1.1 Akış Diyagramı

\section{MALZEME VE YÖNTEM}

Çalışmada 12 farklı hastaya ait 8 bitlik 760*1000 piksel $^{2}$ 'den oluşan X ışını kalp anjiyografi görüntüleri orijinal gri seviye görüntüsü olarak veri kümesine kaydedilmiştir. Bir hastaya ait anjiyografi cihazından alınmış .jpg formatında orijinal anjiyografi görüntüsü Şekil 2.1'de görülmektedir.

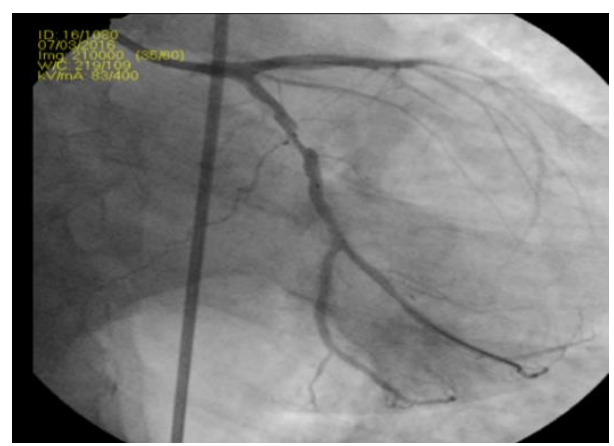

Şekil 2.1 Orijinal anjiyografi görüntüsü

Öncelikle damar üzerinde uzman doktor tarafından tıkalı olarak değerlendirilen kısmın uç noktaları noktasal olarak işaretlenniştir.

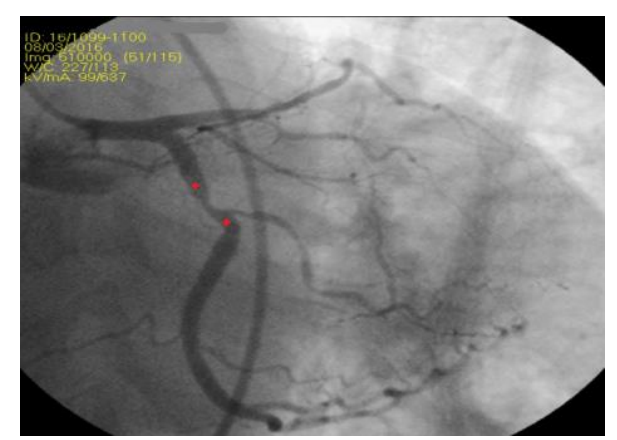

Şekil 2.2 T1kalı bölgenin işaretlenmesi

Daha sonra uzman tarafından işaretlenen bu tıkalı kısmın yatak eksenle yapmış olduğu açı denklem 2.1 kullanılarak belirlenmiştir. Açının belirlenmesinde $\mathrm{P}_{1}\left(\mathrm{x}_{1}, \mathrm{y}_{1}\right)$ ve $\mathrm{P}_{2}\left(\mathrm{x}_{2}, \mathrm{y}_{2}\right)$ ilgili tıkalı kısmın iki uç noktalarını $\Theta^{\circ}$ ise bu ilgili kısmın yatak eksenle yapmış olduğu açıyı ifade etmektedir.

$$
\theta^{\circ}=\arctan \left(\frac{y_{2}-y_{1}}{x_{2}-x_{1}}\right)
$$

Üzerinde çalışılacak kısmın yatay eksenle yaptığı $\Theta$ açısı belirlenmiştir. Böylelikle şekil 2.3'te görüldüğü üzere bu bölgenin görüntü düzleminde yatay olacak şekilde görüntüye $\theta^{\circ}$ kadar döndürme işlemi uygulanmıştır.

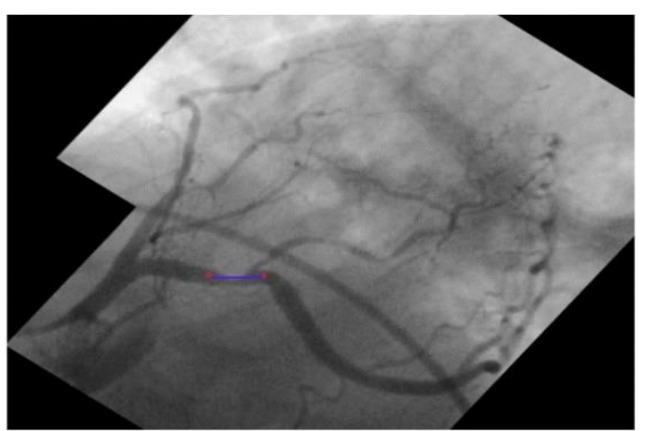

Şekil 2.3 Görüntünün $\theta$ kadar döndürülmesi 
Daha sonra, ilgilenilen bölge orijinal görüntüden çıkartılarak ilgili damar görüntüsü şekil 2.4'te görüldüğü üzere elde edilmiştir.

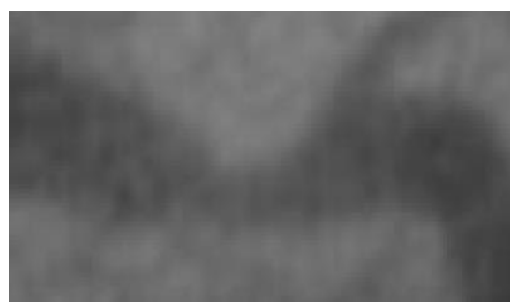

Şekil 2.4 Damarın tıkalı olduğu kısmın görüntüsü

\subsection{Doğrusal Histogram Germe}

Histogram germe işlemi, gri seviye değerlerinin belli bir yerde kümelenmiş olmasından kaynaklanan renk dağılımı bozukluğunu gidermek veya farklılıkların

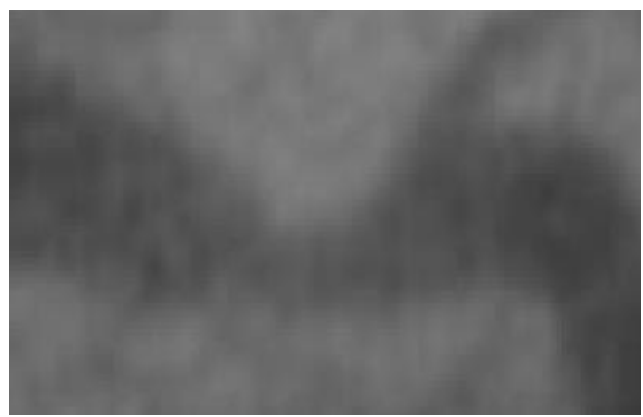

a

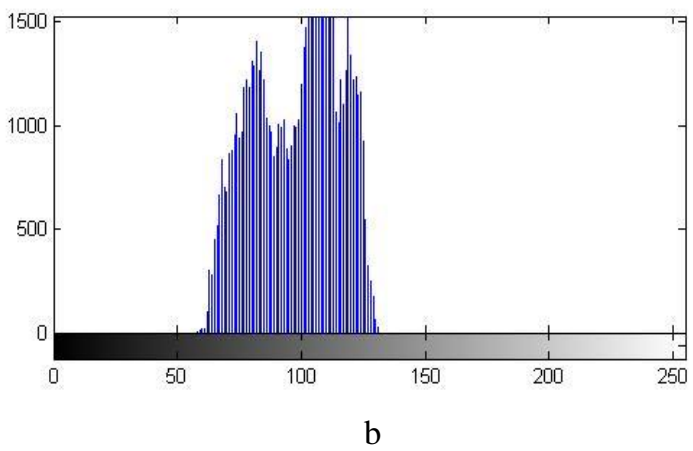

minimuma indirilmesi amaciyla kullanılmaktadır. Sekiz bitlik bir gri seviye görüntüsünde her bir pikselin grilik değeri $\mathrm{f}(\mathrm{x}, \mathrm{y})$, minimum grilik değeri fmin maksimum grilik değeri $f_{\max }$ olarak tanımlanırsa, histogram germe işleminden sonra ilgili pikselin yeni değeri eşitlik 2.2'deki gibi elde edilir.

$$
g(x, y) \frac{f(x, y)-f_{\min }}{f_{\max }-f_{\min }} * 255
$$

Bu sayede görüntü histogramı 0 ile 255 değerleri arasına doğrusal olarak yayılmış olmaktadır. Şekil 2.5 a ve şekil 2.5 b'de tıkalı damar görüntüsü ve görüntü histogramı görülmektedir. Histogram incelendiğinde piksel değerlerinin kümelenmiş olarak dağıldığı görülmektedir. Doğrusal histogram germe yöntemiyle piksel aralıklarının yatay eksen boyunca dağılım gösterdiği Şekil 2.5d'de görülmektedir. Şekil 2.5c'deki elde edilen görüntü incelendiğinde ise damar sınırlarının çok daha belirgin hale geldiği görülmektedir.

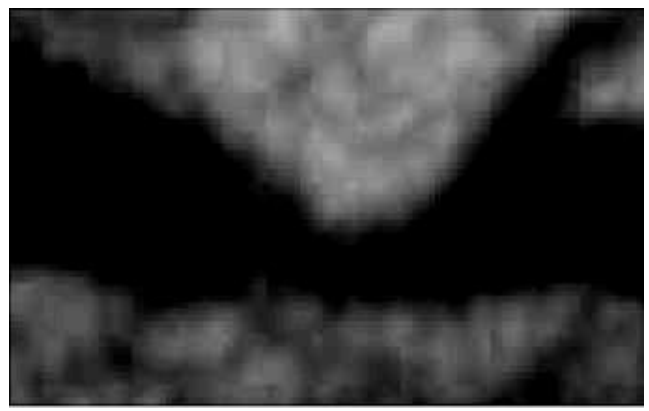

$\mathrm{C}$

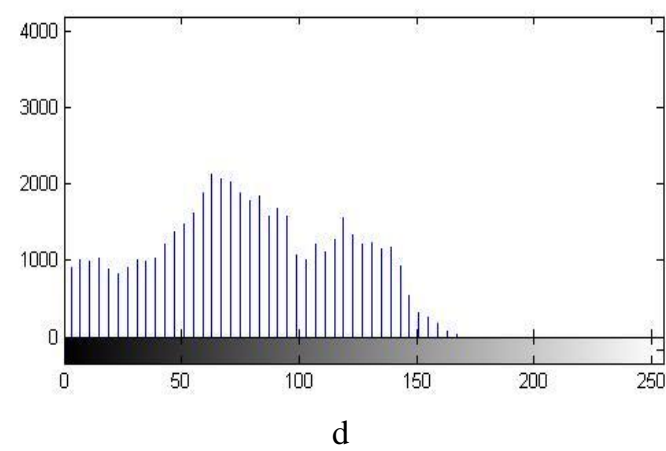

Şekil 2.5 a. Orijinal tıkalı damar bölümü b. a’nın histogramı, c. Lineer histogram germe işlemi sonrası Histogram germe ile elde edilen görüntü ve görüntü histogramı

\section{2. Üç Seviyeli Otsu Metodu}

Histogram germe yöntemiyle önişlemeden geçirilmiş görüntülere, geleneksel Otsu yönteminin geliştirilmiş şekli olan üç seviyeli Otsu yöntemi kullanılarak eşikleme yapılmıştır. Burada eşiklenecek histogram alanını üç kısma ayıracak iki eşik değeri belirlenir. Bu değerin belirlenmesi ise bu üç sınıfın, sınıf içi varyans değerini minimum tutmak ve yine bu üç sınıfın diğer sınıflar arasındaki varyansının maksimum olması mantığına dayanmaktadır. Üç seviyeli Otsu yöntemiyle görüntü histogramını üç sınıfa $\left(\mathrm{C}_{1}, \mathrm{C}_{2}, \mathrm{C}_{3}\right)$ ayıracak iki eşik değeri $\left(T_{1}, T_{2}\right)$ belirlenmektedir. Bu değerler belirlenirken eşik değerleri yerine tüm piksel değerleri konularak sınıflar arası varyans $\sigma_{B}^{2}$ değerleri eşitlik 2.3'te verilen formülle hesaplanır.

$$
\sigma_{B}^{2}=\omega_{1} \mu_{1}^{2}+\omega_{2} \mu_{2}^{2}+\omega_{3} \mu_{3}^{2}-\mu^{2}
$$

Burada $\mu$ tüm görüntünün ortalama piksel değerini ifade ederken, $\omega_{i}$ ve $\mu_{i}$ değerleri ise sırasıyla sınıf 
içi kümülatif moment ve ortalama piksel değerini ifade etmektedir. Sınıf içi varyans değerini minimum, sınıflar arası varyans değerini maksimum yapacak iki değer, $T_{1}$ ve $T_{2}$ eşik değeri olarak belirlenmiştir. $\mathrm{Bu}$ iki değer dışında kalan bölgeler siyah ve beyaz bölgeler olup, arasında kalan gri bölgenin ise sınıf içi varyansı minimum yapan değer, tüm görüntü için optimum eşik değeri olarak belirlenmiştir. Şekil 2.6'da optimum eşik değeri olarak $\mathrm{T}=55$ için eşiklenmiş tıkalı damar bölümü ikili olarak görülmektedir.

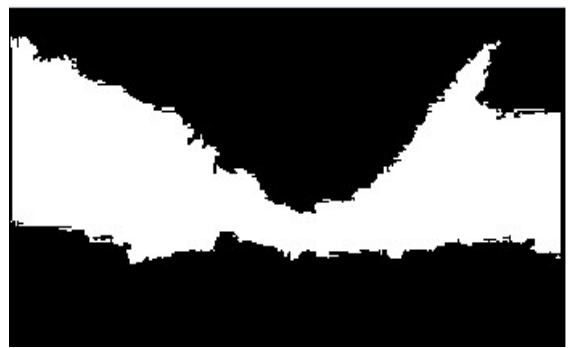

Şekil 2.6 Üç seviyeli Otsu ile eşikleme

\subsection{Darlık Yüzdesinin(DY) belirlenmesi}

Bu kısımda darlaşan bölgenin darlık yüzdesinin (DY) belirlenmesi amacıyla eşiklenerek bölütlenen Şekil 2.6'daki görüntüde damarı temsil eden beyaz pikseller dikey olarak saydırılmıştır. Şekil 2.7'de görüldüğü üzere $\mathrm{d}_{1}$ minimum $\mathrm{d}_{2}$ genişliği maksimum genişliğ $\mathrm{i}$ temsil etmekte olup darlık yüzdesi eşitlik 2.4 'de verilen ifade ile elde edilmiştir.

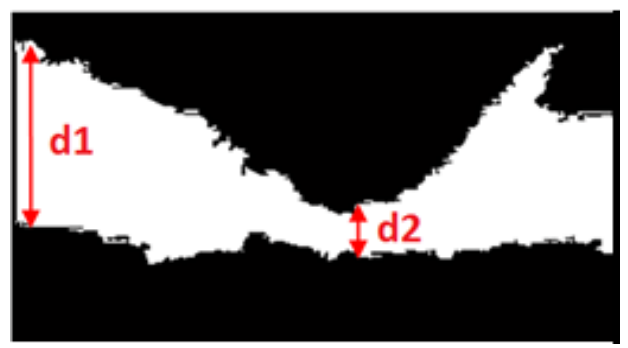

Şekil 2.7 Minimum genişlik ve maksimum genişlikler

$$
\mathrm{DY}=\left(1-\frac{d_{2}}{d_{1}}\right) * 100
$$

Çalışmada kullanılan oniki farklı hastaya ait anjiyografi görüntüleri üzerinde, oluşturulan yazılımla elde edilen ve uzman doktorun elle bölütleme sonucunda belirlediği darlık yüzdeleri tablo 2.1'de görülmektedir. Tablodan da görüleceği üzere, belirlenen her iki darlık yüzdesi değerleri arasında çok küçük farklar mevcuttur. Klinik tecrübesi olan uzman doktorlar, operasyon öncesi darlık yüzdesi belirlerken, tamamen sübjektif oranlar belirleyebilmektedirler. Bu konu tamamen doktorun kişisel tecrübesine bağlı olmakta, doktorlar arasında da tam olarak bir darlık yüzdesi belirlemede birliktelik olmadığ 1 belirtilmektedir.

Tablo 2.1 Elle bölütleme ve otomatik bölütleme ile elde edilen darlık yüzdeleri

\begin{tabular}{|c|c|c|}
\hline $\begin{array}{c}\text { Görüntü } \\
\text { No }\end{array}$ & $\begin{array}{c}\text { Yar1 Otomatik } \\
\text { Bölütleme }\end{array}$ & $\begin{array}{c}\text { Elle } \\
\text { Bölütleme }\end{array}$ \\
\hline 1 & $\% 73$ & $\% 71$ \\
\hline 2 & $\% 75$ & $\% 82$ \\
\hline 3 & $\% 87$ & $\% 93$ \\
\hline 4 & $\% 69$ & $\% 73$ \\
\hline 5 & $\% 63$ & $\% 59$ \\
\hline 6 & $\% 70$ & $\% 73$ \\
\hline 7 & $\% 55$ & $\% 65$ \\
\hline 8 & $\% 59$ & $\% 60$ \\
\hline 9 & $\% 72$ & $\% 68$ \\
\hline 10 & $\% 70$ & $\% 82$ \\
\hline 11 & $\% 57$ & $\% 61$ \\
\hline 12 & & \\
\hline
\end{tabular}

\subsection{ZSI (Zijdenbos Similarity Index)}

Çalışmanın başarısı ZSI (Zijdenbos Similarity Index) başarım belirleme indeksi kullanılarak test edilmiştir. $\mathrm{Bu}$ nedenle öncelikle oluşturulan yazılım sayesinde yarı otomatik bölütlenen alan ile uzman doktor tarafından elle bölütleme sonucunda elde edilen alan üst üste çakıştırılarak, ZSI başarım indeksi belirlenmiştir.
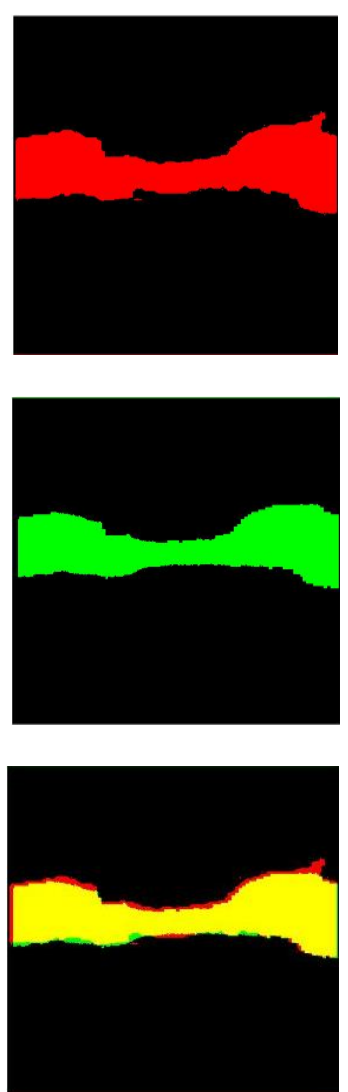

Şekil 2.8 Otomatik ve elle bölütlemenin renkli olarak gösterimi

\section{Yarı Otomatik Bölütleme}

Elle Bölütleme

Yarı Otomatik ve Elle Bölüitleme görüntülerinin üst üste çakıştırılması 
İndeksin belirlenmesinde kullanılan formülasyon eşitlik 2.5 'te görülmektedir.

$$
\mathrm{ZSI}=\frac{2 * \mathrm{O} \cap \mathrm{M}}{|\mathrm{O}|+|\mathrm{M}|}
$$

Şekil 2.8'de otomatik ve elle bölütleme sonucunda elde edilen alanlar kullanılarak, ZSI değerlerinin hesaplanması bir örnek görüntü üzerinde gösterilmiştir. Kırmızı renk oluşturulan yazılım tarafından bölütlenmiş ilgilenilen damar görüntüsünü yeşil renk uzman doktor tarafından elle belirlenmiş damar görüntüsünü göstermektedir. Her iki yöntemle bölütlenmiş damar sınırları üst üste çakıştırıldığında yüksek oranda benzerlik olduğu görülür. Bu çakışan bölümler alttaki resimde sarı renkli olarak gösterilmiştir.

Şekil 2.9'da 12 farklı anjiyo görüntüsünden, yarı otomatik ve elle bölütlemiş alanların çakıştırılmasıyla elde edilen ZSI değerleri verilmiştir. Değerler incelendiğinde 0,78 ile 0,91 arasında değişmektedir. Literatürde, ZSI değerlerinin \% 70'in üzerinde olduğu bölütlemelerin oldukça iyi bir başarıma sahip olduğu belirtilmektedir [11] .

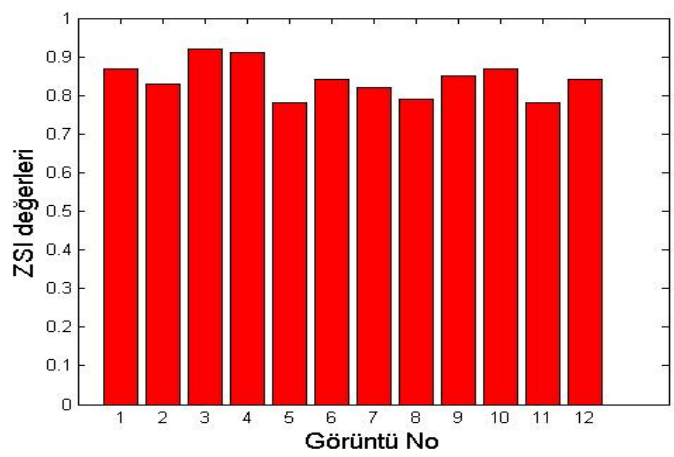

Şekil 2.9 12 farklı hasta için ZSI değerleri

\section{SONUÇLAR}

Çalışmada koroner arter hastalıklarına yol açan damar tıkanıklığının yarı otomatik olarak belirlenmesine yönelik bir yazılım oluşturulmuştur. Oluşturulan yazılımla kalp anjiyografi görüntülerinden tıkalı olan damarın ilgili kısmı bölütlenmiştir. Daha sonra aynı işlem uzman doktor tarafından elle gerçekleştirilerek yarı otomatik bölütlenmiş ve elle bölütlenmiş tıkalı damar kısmı görüntüleri elde edilmiştir. Bölütlenen damar üzerinde minimum genişlik (d1) ve maksimum genişlik (d2) olmak üzere iki değer elde edilmiştir. Bu değerler kullanılarak meydana gelen daralmanın yüzdesi belirlenmiştir. Belirlenen bu darlık yüzdeleri karşılaştırıldığında, oluşturulan yazılım sayesinde belirlenen darlık yüzdeleri ile uzman doktorun elle belirlediği darlık yüzdeleri arasındaki fark oniki görüntüden beşinde $\% 5$ ile $\% 12$ arasında değişirken geri kalan görüntülerde ise $\% 1$ ile $\% 5$ arasında değişmektedir. Ayrıca kullanılan yöntemlerin bölütleme başarımını test etmek amacıyla elle ve otomatik bölütlenen tıkalı damar bölümleri üst üste çakıştırılarak, ZSI başarım belirleme indeksi değerleri elde edilmiştir. Bu değerler 0,78 ile 0,91 arasında değişmekte olup, literatürde yapılmış çalışmalar incelendiğinde başarım için yeterli seviyede değerler olduğu görülmektedir. Elde edilen tüm sonuçlar birlikte değerlendiğinde, oluşturulan yazılımın uzman kardiyologlar için uygun tedavi yönteminin belirlenmesinde yardımc1 olabilecek, alternatif bir yazılım olarak kullanılabileceğini göstermektedir.

\section{KAYNAKLAR}

[1]. Bao S., XU P.,(2006) "New Evolvement in Medical Imaging,", China Medical Devices Information 12(9), 2-5

[2]. Quek F, Kirbas C.,(2001), "Vessel extraction in medical images by wave propagation and traceback” IEEE Trans Med Img 20(2):117-131.

[3]. Khaleel, H. H., Rahmat, R.O. K., Zamrin, D. M., Mahmod R., And Mustapha, N.,(2012). "Extraction of coronary artery trees in angiocardiography images", Scientific Research and Essays, Vol. 7(47), pp. 4014-4036.

[4]. Kaiqiong, S., Nong , S. and Erdun , Z.,( 2005), "Extraction of Vascular Tree on Angiogram with Fuzzy Morphological Method", International Journal of Information Technology, Vol.11 No. 9.

[5]. Y Qian, S Eiho, N Sugimoto, M Fujita, (1998) "Automatic Extraction of Coronary Artery Tree on Coronary Computers in Cardiology,", IEEE

[6]. Truc, P. T. H., Khan M. A. U., Lee Y-K., Lee S., and Kim, T-S., (2009). "Vessel enhancement filter using directional filter bank", Computer Vision and Image Understanding, 101-112.

[7]. Pal, N. R. and Pal, S. K., (1989)."Entropy thresholding", Signal Proc. Vol. 16, pp.97-108.

[8]. Şengür, A., Türkoğlu, İ., İnce, M.C,( 2005). "İki Boyutlu Entropi İle Görüntü Eşikleme Uygulamaları ", SíU Konferansı,

[9]. R. I. Kakihara,(2004) “A Noninvasive Alternative to Coronary Angiography: Myocardial Contrast Echocardiography Following Strain Map as a Gate Way to Myocardial Contrast Echocardiography Map,' 3th International Conference on Cardiology, vol. 5, pp. 74-77.

[10]. Kirbas, C., Quek, FKH., (2003). "Vessel Extraction Techniques and Algorithms" A Survey. In Third IEEE Symposium on BioInformatics and BioEngineering 238-245.

[11]. Alkan A, Tuncer SA, Gunay M., (2014) Comparative MR image analysis for thyroid nodule detection and quantification, Measurement, Volume 47, , Pages 861-868. 